\title{
DEVELOPMENT OF THE PULSE TRANSFORMER FOR NLC KLYSTRON PULSE MODULATOR*
}

\author{
M. Akemoto ${ }^{\dagger}$, S. Gold, A. Krasnykh and R. Koontz \\ Stanford Linear Accelerator Center, Stanford University, Stanford CA 94309
}

DISCLAIMER

\begin{abstract}
This report was prepared as an account of work sponsored by an agency of the United States Government. Neither the United States Government nor any agency thereof, nor any of their employees, makes any warranty, express or implied, or assumes any legal liability or responsibility for the accuracy, completeness, or usefulness of any information, apparatus, product, or process disclosed, or represents that its use would not infringe privately owned rights. Reference herein to any specific commercial product, process, or service by trade name, trademark, manufacturer, or otherwise does not necessarily constitute or imply its endorsement, recommendation, or favoring by the United States Government or any agency thereof. The views and opinions of authors expressed herein do not necessarily state or reflect those of the United States Government or any agency thereof.
\end{abstract}

\section{Abstract}

We have studied a conventional pulse transformer for the NLC klystron pulse modulator. The transformer has been analyzed using a simplified lumped circuit model. It is found that a fast rise time requires low leakage inductance and low distributed capacitance and can be realized by reducing the number of secondary turns, but it produces larger pulse droop and core size. After making a tradeoff among these parameters carefully, a conventional pulse transformer with a rise time of $250 \mathrm{~ns}$ and a pulse droop of $3.6 \%$ has been designed and built. The transmission characteristics and pulse time-response were measured. The data were compared with the model. The agreement with the model was good when the measured values were used in the model simulation. The results of the high voltage tests are also presented.

Presented at the IEEE Particle Accelerator Conference (PAC 97)

Vancouver, B.C., Canada

May 12-16, 1997

"Work supported by Department of Energy contract DE-AC03-76SF00515.

${ }^{\dagger}$ Visiting from KEK, permanent address: 1-1 Oho, Tsukuba-shi, Ibaraki-ken 305 Japan. 


\section{DISCLAMIXR}

Portions of this document may be illegible in electronic image products. Images are produced from the best available original document. 


\title{
DEVELOPMENT OF THE PULSE TRANSFORMER FOR NLC KLYSTRON PULSE MODULATOR*
}

\author{
M. Akemoto ${ }^{\dagger}$, S. Gold, A. Krasnykh and R. Koontz \\ Stanford Linear Accelerator Center, Stanford University, Stanford, CA 94309, USA
}

\section{Abstract}

We have studied a conventional pulse transformer for the NLC klystron pulse modulator. The transformer has been analyzed using a simplified lumped circuit model. It is found that a fast rise time requires low leakage inductance and low distributed capacitance and can be realized by reducing the number of secondary turns, but it produces larger pulse droop and core size. After making a tradeoff among these parameters carefully, a conventional pulse transformer with a rise time of $250 \mathrm{~ns}$ and a pulse droop of $3.6 \%$ has been designed and built. The transmission characteristics and pulse time-response were measured. The data were compared with the model. The agreement with the model was good when the measured values were used in the model simulation. The results of the high voltage tests are also presented.

\section{INTRODUCTION}

The klystron pulse modulator for the Next Linear Collider(NLC) requires to produce a $500 \mathrm{kV}, 530 \mathrm{~A}, 1.5 \mu \mathrm{s}$ flat top pulse to drive a pair of PPM-focused 75MW klystron[1]. The R\&D of basic elements, a charging supply, a PFN, a thyratron switch tube and a pulse transformer for a prototype NLC modulator are being performed at SLAC[2].

The power efficiency of the modulator is extremely important. The effective output power of the modulator is the power of the flat-top portion of the high voltage output pulse. Since a pulse transformer is a major contributor to the waveform, the pulse transformer requires a fast rise time. In order to achieve a rise time that is less than $400 \mathrm{~ns}$, we have improved the design of a 14:1 pulse transformer by tradeoffs among the droop, the core size and the rise time. The test transformer has been built, and low and high voltage tests have been performed.

\section{ANALYSIS OF THE PULSE TRANSFORMER}

In order to simplify the analysis, we consider the simple geometrical arrangement with rectangular core. A singlelayer secondary is wound over a one-layer primary and the distance between layers is constant[3].

\subsection{Equivalent circuit}

Figure 1 shows an equivalent circuit for the pulse transformer. The $L_{p}$ is primary inductance, the $L_{S}$ is secondary inductance, the $L_{L}$ is leakage inductance, the $C_{D}$ is distributed capacitance, the $L_{D}$ is distributed leakage inductance. These circuit elements can be calculated from the geometrical constants of the transformer, dielectric constant of the insulation, and the permeability of the core material.

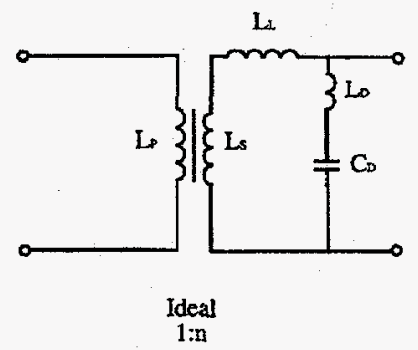

Figure 1. Equivalent circuit for the pulse transformer.

\subsection{Droop and core size}

The droop $D_{r}$ is given by

$$
D_{r}=\frac{R_{k l y \cdot \tau}}{2 L_{s}}
$$

where $R_{k l y}$ is klystron impedance, $\tau$ the pulse width and $L_{s}$ the secondary inductance.

The cross-section area of the core $A$ is given by

$$
A=\frac{V_{s} \tau}{\Delta B} \frac{1}{N_{s}}
$$

where $V_{S}$ is the voltage of secondary, $N_{S}$ the number of secondary turns and $\triangle \mathrm{B}$ the total magnetic flux density swing of the core. Thus, the cross-sectional area of the core is inversely to proportional to the number of secondary turns.

Since the secondary inductance $L_{S}$ is calculated by

$$
L_{s}=\frac{\mu_{0} \mu_{e} e^{A \cdot N_{s}^{2}}}{l},
$$

where $\mu_{0}$ is the permeability of free space, $\mu_{\mathrm{e}}$ the effective magnetic permeability, $l$ the length of the magnetic path. Thus, the droop $D_{r}$ is given by

$$
D_{r}=\frac{\Delta B \cdot R_{k l y}}{2 \mu_{0} \mu_{e} V_{s}} \frac{l}{N_{s}} \text {. }
$$

The droop is propoportinal to the length of the magnetic path and inversely to proportional to the number of secondary turns.

\subsection{Rise time}

The rise time $t_{\mathrm{T}}$ is determined by

$$
t_{r} \propto \sqrt{L_{L} \cdot C_{D}} \text {. }
$$

The leakage inductance $L_{L}$ is calculated by

*Work supported by the Department of Energy contract DE-AC03-76SF00515.

+ Visiting from KEK, permanent address: 1-1 Oho, Tsukuba-shi, Ibaraki-ken 305 Japan. 


$$
L_{L} \propto \frac{\mu_{0} \Delta \cdot u \cdot N_{s}^{2}}{L}
$$

where $\Delta$ is the distance between layers, $u$ the average circumference of the layers and $L$ the winding length.

The distributed capacitance $\mathrm{C}_{\mathrm{D}}$ is calculated by

$$
C_{D} \propto \frac{\varepsilon_{0} \varepsilon_{r} u \cdot L}{\Delta}\left(\frac{n-1}{n}\right)^{2}
$$

where $\varepsilon_{0}$ is permittivity constant of free space, $\varepsilon_{r}$ the dielectric constant of the insulation and $\mathrm{n}$ turn ratio. Therefore, from using $u=4 \sqrt{A}+\pi \Delta$, the rise time is given by

$$
t_{r} \propto \sqrt{\varepsilon_{r}} \sqrt{\frac{V_{s} \cdot \tau}{\Delta B}} \sqrt{N_{s}} \frac{n-1}{n} .
$$

It is found that the rise time strongly depends on the number of the secondary turns rather than turn ratio.

\subsection{Tradeoffs}

From the above analysis, it is found that a fast rise time requires low leakage inductance and low distributed capacitance and can be realized by reducing the number of secondary turns, but it produces larger pulse droop and core size. Thus, fast rise time and low droop are contrary to each other. Since a droop of several percentage can be compensated by making adjustments to the PFN, we can improve the rise time by tradeoffs among these parameters.

\section{FABRICATION OF TEST PULSE TRANSFORMER}

The conventional pulse transformer has been carefully optimized and designed by the model calculations. The transformer is an isolation transformer type with two parallel primary basket windings, and with two parallel tapered secondary basket windings as shown in Figure 2. It has been fabricated by Stangenes Industries, Inc.

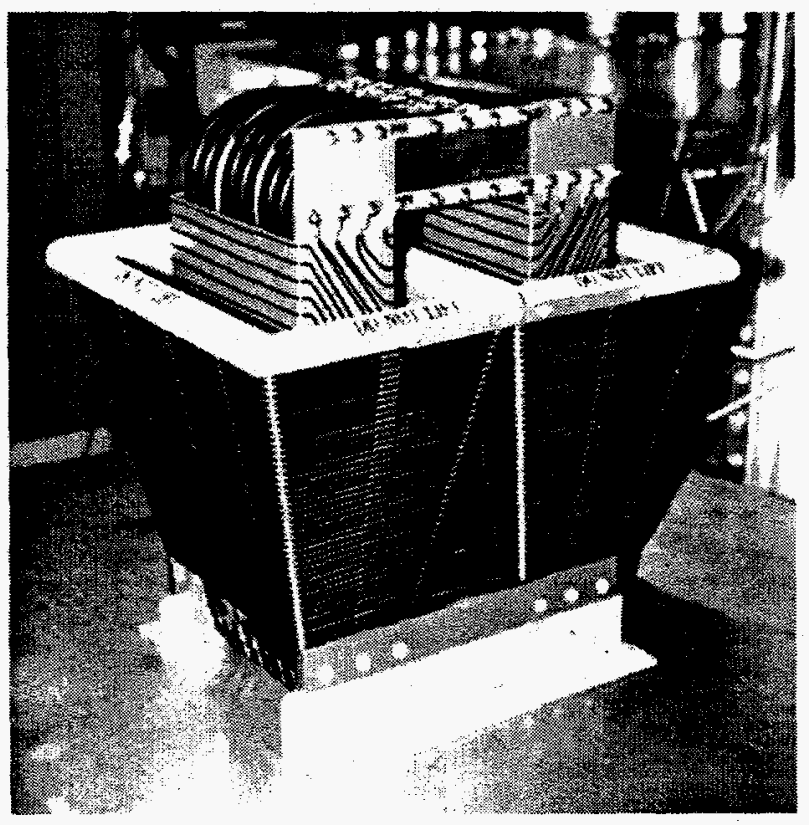

Figure 2. Side view of the pulse transformer.
Parallel primaries and secondaries are wound on each leg providing bifilar characteristics. The core is made up of 3 smaller subcores strapped together. Each subcore is wound from 0.002 -inches thick, silectron grain-oriented silicon steel ribbon. Table 1 and 2 shows specifications and parameters of the pulse transformer, respectively.

\begin{tabular}{|c|c|c|}
\hline Parameters & unit & \\
\hline Total magnetic flux density swing & $\mathbf{T}$ & 2.0 \\
\hline Effective magnetic permeability & & 1,500 \\
\hline Core packing factor & $\%$ & \\
\hline Area of the core & $\mathrm{m}^{2}$ & 0.0102 \\
\hline $\begin{array}{l}\text { Distance between layers in the } \\
\text { high-voltage side }\end{array}$ & $\mathrm{mm}$ & \\
\hline $\begin{array}{l}\text { Distance between layers in the } \\
\text { low-voltage side }\end{array}$ & $\mathrm{mm}$ & 6 \\
\hline Mean magnetic-path length & $\mathbf{m}$ & 1.04 \\
\hline Effective winding length & $\mathrm{mm}$ & 260 \\
\hline $\begin{array}{l}\text { Circumference of the primary } \\
\text { layer in the low-voltage side }\end{array}$ & $\mathrm{mm}$ & 538 \\
\hline Number of primary turns & turns & 3 \\
\hline Number of secondary turns & turns & 42 \\
\hline
\end{tabular}

\begin{tabular}{cc} 
Table 1 . Specification of the pulse transformer \\
\cline { 1 - 2 } Primary voltage & $33.2 \mathrm{kV}$ \\
Primary current & $5320 \mathrm{~A}$ \\
Secondary voltage & $465 \mathrm{kV}$ \\
Secondary current & $380 \mathrm{~A}$ \\
Output impedance & $1224 \Omega$ \\
Flat top pulse width & $1.5 \mu \mathrm{s}$ \\
Pulse droop & $3.6 \%$ \\
Rise time & $250 \mathrm{~ns}$ \\
Turn ratio & $1: 14$ \\
Pulse repetition rate & $180 \mathrm{pps}$ \\
\hline
\end{tabular}

Table 2. Parameters of the pulse transformer

\section{LOW VOLTAGE TEST[4]}

\subsection{Electrical parameters}

The primary inductance, secondary inductance, leakage inductance and the distributed capacitance between the primary and the secondary windings were measured in air with a LCR meter (BK Precision 875A). In the model calculation, the shape of the tapered basket and distribution of voltage along the windings were considered. The measured and calculated values are summarized in Table 3 . It should be note that the calculated value does not include the inductance of the shorting strap across the primary. If the shorting is $100 \mathrm{nH}, 19.6 \mu \mathrm{H}$ should be subtracted from measured value. We are investigating the discrepancy between the calculations and the measurements.

Table 3. Electrical parameters for the pulse transformer

\begin{tabular}{llll}
\hline Item & unit & $\begin{array}{l}\text { Model calculated } \\
\text { value }\end{array}$ & $\begin{array}{l}\text { Measured } \\
\text { value }\end{array}$ \\
\hline Primary Inductance & $\mu \mathrm{H}$ & 130 & 55.2 \\
Secondary Inductance & $\mathrm{mH}$ & 25.48 & 10.81 \\
Distributed capacitance & $\mathrm{pF}$ & 25 & 33 \\
Leakage inductance & $\mu \mathrm{H}$ & 80.36 & 122.2 \\
\hline
\end{tabular}

\subsection{Transmission characteristics}

The transmission characteristics of the pulse transformer were measured in air with the network analyzer(HP 3577A). The test circuit is shown in Figure 3. 


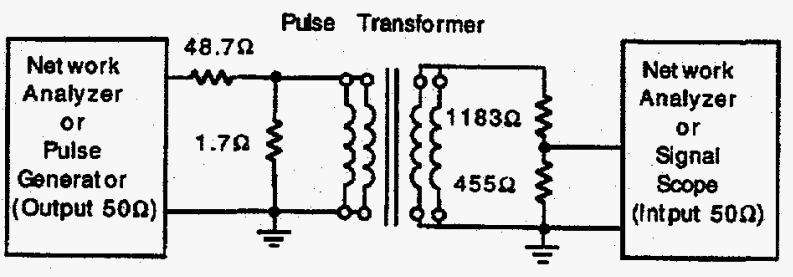

Figure 3. Test circuit.

Figure 4 shows the data of the amplitude and phase for the transformer as a function of frequency. A remarkable feature of the measurement data is a prominent sharp dip at $7.198 \mathrm{MHz}$. This frequency corresponds to $1 / 2 \pi \sqrt{ } \mathrm{L}_{D} \mathrm{C}_{\mathrm{D}}$. Therefore, the distributed inductance $L_{D}$ is determined to be $14.8 \mu \mathrm{H}$ by using measured distributed capacitance. The broken curve in this figure shows result simulated by a computer code Micro-Cap IV using electrical parameters of the measured values. The simulation gives a good fit to the data.
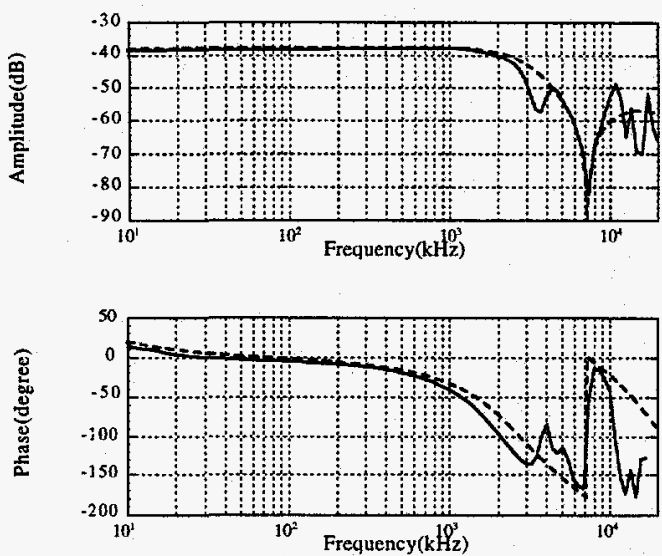

Figure 4. Amplitude and phase for the pulse transformer as a function of frequency.

\subsection{Pulse response}

A square low-voltage pulse signal with a width of $2 \mu \mathrm{s}$ was fed to the primary side, and the output pulse waveform was measured in air with the oscilloscope as shown in Figure 3. The result is shown in Figure 5. The rise time (10-90\%) was $190 \mathrm{~ns}$. The broken curve in this figure shows simulated result. The simulation gives a good fit to the data.

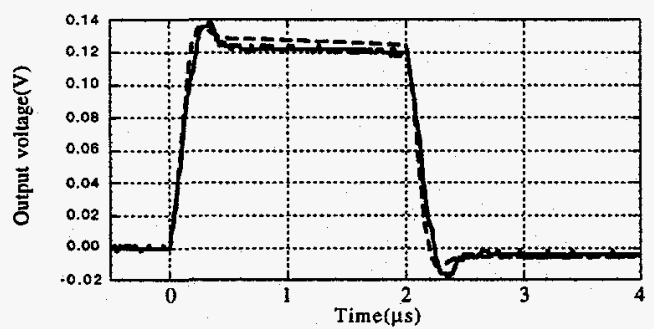

Figure 5. Pulse response of the pulse transformer.

\section{HIGH VOLTAGE TEST IN OIL}

The high voltage test of the pulse transformer connected to a 5045 klystron has performed. The transformer was installed in the Test Stand 3 modulator oil tank. Figure 6 shows an example of the klystron voltage waveform. The PFN was not adjusted to make a flat-top. A high voltage pulse with a rise time of $380 \mathrm{~ns}(10-90 \%)$ was successfully generated. The broken curve in this figure shows simulated result. In this case, a total of distributed capacitance included klystron and tank was estimated to be $250 \mathrm{pF}$.

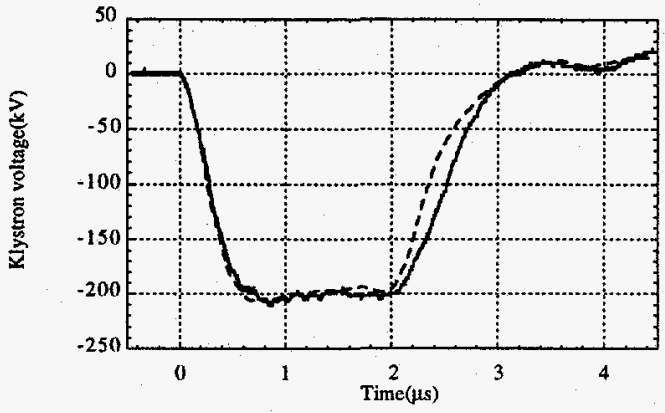

Figure 6. Output pulse waveform at the klystron.

\section{SUMMARY}

For the NLC klystron pulse modulator, we have improved pulse transformer design of 14 to 1 ratio by tradeoffs among the droop, the core size and the rise time. In the high voltage test of the transformer using a klystron load, a rise time of $380 \mathrm{~ns}$ was successfully generated. The data calculated by the lumped circuit model are in agreement with the measured data. The model can also be used to optimize the design further.

\section{ACKNOWLEDGEMENTS}

The authors wish to thank George Caryotakis and Ronald Ruth for their support of this project.

\section{REFERENCES}

[1] The NLC Design Group: 'Zeroth-Order Design Report for the Next Linear Collider', SLAC-474, 1996.

[2] R. Koontz, M. Akemoto, S. Gold, A. Krasnykh and Z. Wilson: 'NLC Klystron Pulse Modulator R\&D at SLAC', this cnference.

[3] N. G Glasoe and J.V. Lebacqz: 'Pulse Generators', Massachusetts Institude of Technology Radiation Laboratory Series, vol. 5, McGraw-Hill Book Company, New York, 1948.

[4] M. Akemoto and S. Gold: "Analysis of the pulse transformer by a lumped circuit model', to be published. 